\title{
12 RISK OF FRACTURE IN CHILDREN WITH EPILEPSY: A COHORT STUDY USING THE GENERAL PRACTICE RESEARCH DATABASE
}

doi:10.1136/injuryprev-2012-040590d.12

V Prasad, J West, D Kendrick, K Sayal. University of Nottingham, UK

Background Epilepsy is thought to be associated with an increased risk of fractures but information on the estimated risk, especially in children, has been limited. Childhood injuries, including fractures, are a leading cause of morbidity and mortality in the UK and worldwide. Aims To measure the rates of fracture injuries in children and young people with epilepsy aged 0-24 years compared to children without epilepsy in the UK primary care population.

Methods A historical cohort study was conducted using data from the General Practice Research Database (GPRD) from 1 January 1987 to 31 December 2009. All participants with epilepsy (aged 024 years) were frequency-matched, by 5 -year age band and practice, to up to five participants without epilepsy. Incidence rate ratios for fracture were estimated and adjusted for potential confounders.

Results/0utcome There were a total of 100524 in the cohort. Of these 74206 did not have epilepsy and 22143 had epilepsy based on our inclusion criteria. Final results from the analysis on fracture rates will be presented at the conference.

Significance/Contribution to the Field Accurate estimates of the risk of fracture in children with epilepsy compared to children without epilepsy would be useful to inform treatment decisions, educate families on fracture risk at the point of diagnosis and to inform lifestyle choices. 